\title{
Complex regional pain syndrome in the young male population: a retrospective study of $\mathbf{2 0 0}$ Korean young male patients
}

\author{
Ho-Jin Lee ${ }^{1}$, Chang-Soon Lee ${ }^{1}$, Yongjae Yoo ${ }^{1}$, Jae Mun Noh ${ }^{1}$, Je Hyuk Yu $^{1}$, Yong-Chul Kim ${ }^{1,2}$, and Jee Youn Moon ${ }^{1,2}$ \\ 'Department of Anesthesiology and Pain Medicine, Seoul National University Hospital, Seoul, Korea \\ ${ }^{2}$ Department of Anesthesiology and Pain Medicine, Seoul National University College of Medicine, Seoul, Korea
}

Received March 6, 2019

Revised May 31, 2019

Accepted July 5, 2019

\section{Correspondence}

Jee Youn Moon

Department of Anesthesiology and Pain Medicine, Seoul National University Hospital, Seoul National University College of Medicine, 101 Daehak-ro, Jongno-gu, Seoul 03080, Korea

Tel: +82-2-2072-2462

Fax: +82-2-763-9390

E-mail: jymoon0901@gmail.com

Previous presentation at conferences: The 66th Korean Pain Society Scientific Meeting \& Training Course, 26th May. 2018, Changwon Exhibition Convention Center, Changwon, Korea.

Key Words

Chronic Pain

Complex Regional Pain Syndrome

Epidemiology

Male

Military Medicine

Military Personnel

Neuralgia

Psychological Stress
Background: The aim of this study was to investigate the clinical characteristics of complex regional pain syndrome (CRPS) in young male patients in South Korea, especially focusing on the association with military service.

Methods: From January 2007 to May 2017, we investigated the electronic medical records of 430 consecutive patients, aged 18 to 30 years, who visited Seoul National University Hospital Pain Center, with a suspected diagnosis of CRPS at the initial visit. The following patient details were available for analysis: demographic and disease-related variables, relevance to military service, medications, and the treatment modalities received.

Results: Out of 430 patients, 245 (57.0\%) were diagnosed with CRPS, of which, 200 were male patients and 45 were female patients. Of the male patients, 95 (47.5\%) developed CRPS during military service. CRPS during military service was more likely to result from sprain/strain, and the incidence of CRPS was significantly higher in the lower extremities in patients from the military service group than in those from the non-military service group. During the follow-up period, $37.9 \%$ of male CRPS patients ( $n=61 / 161)$ were treated successfully. Patients with moderate to severe initial pain intensity, and diagnosed during their military service, showed better outcomes.

Conclusions: Our results demonstrated that manifestation of CRPS in the young Korean population was more common in male and among those male CRPS patients, about half the cases developed during the military service period.

\section{INTRODUCTION}

Complex regional pain syndrome (CRPS) is a set of signs and symptoms characterized by continuing regional pain that is seemingly disproportionate in time or degree to the usual course of pain after trauma or other injury [1]. The lesion in CRPS usually has a distal predominance of abnormal sensory, motor, sudomotor, vasomotor edema, and/or trophic findings. It significantly affects the quality of life and daily functioning of the patient as it causes severe pain with resultant psychosocial and socioeconomic adverse effects [2].

In general, CRPS has been more common in female, and the incidence increases with age $[3,4]$. However, reports of previous epidemiological studies of CRPS in Korea have been controversial. One previous single-center retrospective study that included 150 CRPS patients reported that in Korea, the condition was more prevalent in male than (c) This is an open-access article distributed under the terms of the Creative Commons Attribution Non-Commercial License (http://creativecommons.org/licenses/by-nc/4.0/), which permits unrestricted non-commercial use, distribution, and reproduction in any medium, provided the original work is properly cited.

(C) The Korean Pain Society, 2019
Author contributions: Ho-Jin Lee: Writing/manuscript preparation; Chang-Soon Lee: Formal analysis; Yongjae Yoo: Data curation; Jae Mun Noh: Data curation; Je Hyuk Yu: Data curation; Yong-Chul Kim: Study conception; Jee Youn Moon: Supervision. 
in female, and was especially common in the third and fifth decades [5]. Among those patients, $73 \%$ of patients in the third decade (16/22 patients) were obligatory military service soldiers. However, it may be difficult to generalize the results since only 22 subjects in the third decade were included in the study. Another study utilizing electronic population health data demonstrated that the incidence rate of CRPS in Korea was higher in females, which was in agreement with the demographic distribution in other countries, and peak incidence was observed in the 70s age group [4,6-8]. Although this study analyzed a large population using the National Health Insurance Service, the results might be not be exact since diagnosis of CRPS was not made in a homogeneous manner with consensus.

Epidemiology of a disease may be influenced by a special social condition. Korea is the only divided country in the world, which is currently in a state of armistice with North Korea, and all healthy young adult male are required to serve in the military. According to the Korean Military Manpower Administration, a total of 227,115 soldiers were enlisted in the army in 2017 [9]. These soldiers have a duty of national defense, and further, after the 2-year military service, they form an important part of the work force in Korean society. Therefore, if a specific disease, such as CRPS, is more prevalent in this young male population, and is especially associated with military service in South Korea, it can be an important social issue, which increases not only the individual but also the national health burden. However, to the best of our knowledge, the potential association between the incidence of CRPS and military service in the young male population has never been analyzed in detail.

Therefore, the aim of this study was to investigate the clinical characteristics of CRPS in young male patients in South Korea, especially focusing on the association with their military service status.

\section{MATERIALS AND METHODS}

\section{Study design and ethics statement}

This retrospective study was approved by the Institutional Review Board of Seoul National University Hospital (IRB No. 1410-046-61), a tertiary national university-based civilian hospital, and the study adhered to the applicable STROBE guidelines [10]. We reviewed electronic medical records of 430 consecutive patients aged 18 to 30 years who visited Seoul National University Hospital Pain Center between January 2007 and May 2017, with a suspected diagnosis of CRPS at the initial visit. Patients with suspected CRPS were defined as those with a differential diagnosis of
CRPS in the medical records at the first visit.

To diagnose CRPS, we used a standardized assessment protocol that included the CRPS database checklist of signs and symptoms (as described by the Budapest research criteria) [11]. Patients reported more than one symptom in each of the following 4 categories of the $\mathrm{Bu}$ dapest research criteria: sensory (spontaneous pain, and hyperalgesia and/or allodynia); vasomotor; sudomotor/ edema; and motor (weakness, tremor, and/or dystonia)/ trophic (skin, hair, nails). In addition, patients were required to have at least 2 signs from the same 4 categories, identified at initial evaluations. For objective evaluation of the signs of CRPS, quantitative sensory testing was administered to assess the threshold of the vibration and cooling sensations of the affected and contra-lateral extremities. To evaluate temperature asymmetry, we applied digital infrared thermography, and determined the temperature in the region of interest, as well as in the contralateral region, and considered the test to be positive when the difference in temperature between 2 parts was greater than $1^{\circ} \mathrm{C}$ [12]. Autonomic nervous system function was evaluated using the sympathetic skin response, the deep breath test, and the orthostatic test. Objective tests, such as the quantitative sudomotor axon reflex test, three-phase bone scintigraphy, simple X-ray imaging with or without bone densitometry, electromyogram, and nerve conduction velocity were also used for assessment. Trophic changes, skin color asymmetry, and asymmetric edema were recorded by photographs attached to each patient's chart. Psychological assessments were performed in cases that entailed any possibility of secondary gain or litigation.

The following patient details were available for analysis: age; sex; diagnosis (CRPS, post-traumatic pain syndrome, or others); if diagnosed with CRPS, the type of CRPS (CRPS type I or II); injury sites (upper or lower extremity, or bilateral); laterality (unilateral or bilateral); etiology (sprain/strain, post-surgical, fracture, contusion/crush injury, local inflammation, traffic accident, spontaneous attack without injury, or others or unknown); the medical institution that referred the patient to our hospital; history of past treatment before the initial outpatient visit; pain intensities at the initial outpatient visit and at the last visit using an 11-point verbal numerical rating scale (NRS); duration of CRPS symptoms prior to our pain center evaluation; relevance to military service; medication (opioids, anticonvulsants, and/or antidepressants); history of psychiatric treatment after the initial outpatient visit; and the treatment modalities received (sympathetic block, epidural block, spinal cord stimulator [SCS] implantation or removal, and/or implantation of a drug delivery system, such as the intrathecal morphine pump). All incidents in the army during military service were defined as events 
related to military service, which included not only military training but also sports and daily activities in the army. Regarding treatment outcome, "treatment success" was defined as a pain reduction of more than $50 \%$ or a decrease of more than 3 NRS points [13] or an NRS score $\leq 4$ at the last outpatient visit.

\section{Statistical analysis}

First, patients diagnosed with CRPS were divided into 2 groups according to sex (male vs. female) and the differences between the clinical variables in the 2 groups were compared. Then, to explore the association between the incidence of CRPS and military service in the young male population, male patients were sub-divided into the military service group and non-military service group, and a comparison of the 2 groups was carried out. In addition, to evaluate the treatment outcome related with other variables in male CRPS patients, we performed binary logistic regression analysis using a backward stepwise conditional method. The treatment outcome was a dependent variable, defined in a dichotomous manner as "success" or "failure" based on pre-defined success criteria. The following varaibles were included in the analyses; age (yr), duration of CRPS sympatoms (mo), type of CRPS (type 1 and 2), NRS at first outpatient visit (mild, NRS 1-4; moderate, NRS 5-7; severe, NRS 8-10), relevance to military service, affected extremity, and treatment modalities. In multivariable analysis, we included variables that showed trends suggestive of statistical significance $(P<0.2)$ in univariable analyses.

Statistical analysis was performed using the SPSS Statistics program ver. 21.0 (IBM Corp., Armonk, NY) for Windows. All parametric data were presented as mean \pm standard deviation (SD) and nonparametric data were presented as numbers and proportions. All parametric data were expressed as mean \pm SD and compared between the 2 groups using the Student's $t$-test. All nonparametric data were compared using the Mann-Whitney test and expressed as median (interquartile range). Categorical data were analyzed using the chi-square test or Fisher's exact test as appropriate. $P$ values $<0.05$ were considered statistically significant.

\section{RESULTS}

A total of 430 patients who visited Seoul National University Hospital Pain Center between January 2007 and May 2017 were suspected to have CRPS. Among them, 294 patients $(68.4 \%)$ were male and $136(31.6 \%)$ were female (male to female ratio, 2.2:1.0). Of these, 200 males $(68.0 \%)$ and only 45 females (33.1\%) were diagnosed with CRPS (Fig. 1).

The demographics of the 245 patients who were diagnosed with CRPS are described in Table 1. The age at onset was significantly lower in male patients than in female patients $(P=0.015)$. Lesions in the lower extremities were more frequent than those in the upper extremities in both male and female patients; the lesions were mostly unilateral. In male CRPS patients, 95 cases $(47.5 \%)$ were associated with military service, whereas there was no female who was involved in military service. In terms of etiology, surgical procedure was the most common etiology (27.1\%), followed by sprain/strain (24.1\%), and contusion/crush injury (22.6\%) in males, whereas in females, traffic accident was the most frequent etiology (31.1\%), followed by surgical procedure (26.7\%) and contusion/crush injury (15.6\%).

In terms of the characteristics of male CRPS patients according to their military service associations, of the 200 male patients diagnosed with CRPS, 95 cases (47.5\%) were associated with CRPS-related events during their military service period (Table 2). All patients were soldiers who were on duty for 2-year military service, not professional soldiers. The age at first visit was significantly lower and the duration of illness was shorter in the military service group than in the non-military service group $(P=0.024$

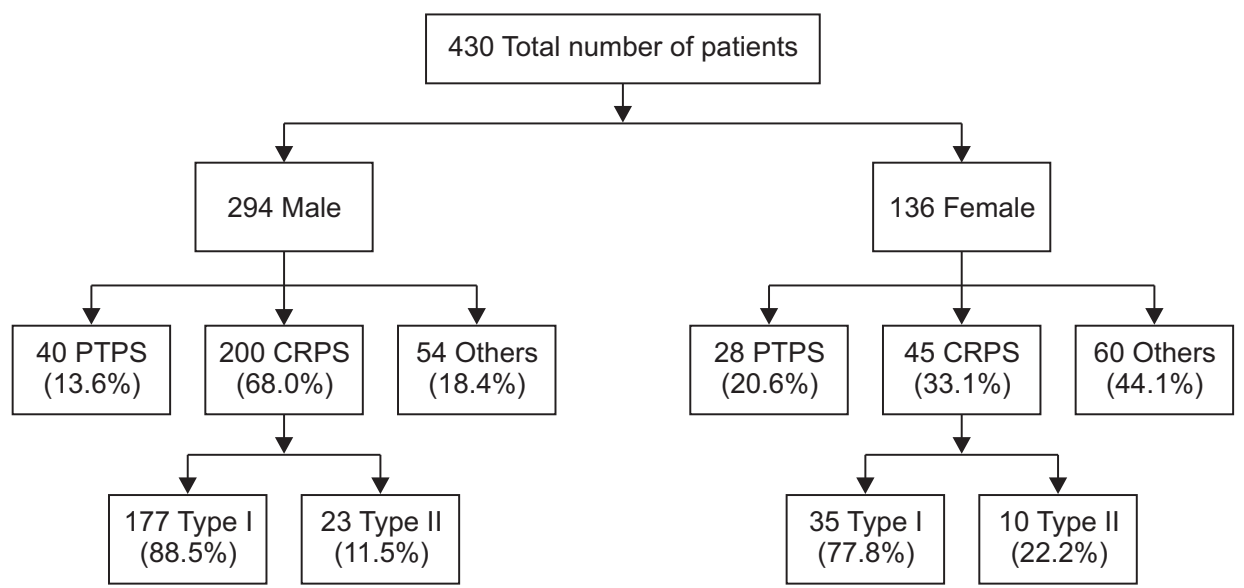

Fig. 1. Diagnostic distribution of this study. PTPS: post-traumatic pain syndrome, CRPS: complex regional pain syndrome. 
Table 1. Demographics and Clinical Variables of Patients with Suspicious CRPS at the 1st Visit

\begin{tabular}{|c|c|c|c|c|}
\hline Variable & Total $(n=245)$ & Male $(n=200)$ & Female $(n=45)$ & $P$ value \\
\hline Age (yr) & $22(20-26)$ & $21(20-24)$ & 27 (20-29) & 0.015 \\
\hline Duration (mo) & $8(4-15)$ & $8(4-14)$ & $9(2-19)$ & 0.358 \\
\hline Initial NRS (0-10) & $7(6-9)$ & $7(6-9)$ & $7.5(6-9)$ & 0.322 \\
\hline Etiology & & & & 0.003 \\
\hline Sprain/Strain & $52(21.2)$ & $48(24.0)$ & $4(8.9)$ & \\
\hline Post-surgical & $66(26.9)$ & $54(27.0)$ & $12(26.7)$ & \\
\hline Fractures & $8(3.3)$ & $6(3.0)$ & $2(4.4)$ & \\
\hline Contusion/Crush injury & $52(21.2)$ & $45(22.5)$ & 7 (15.6) & \\
\hline Local inflammation & $3(1.2)$ & $3(1.5)$ & $0(0.0)$ & \\
\hline Traffic accident & $33(13.5)$ & $19(9.5)$ & $14(31.1)$ & \\
\hline Spontaneous & $19(7.8)$ & $17(8.5)$ & $2(4.4)$ & \\
\hline Other or unknown & $12(4.9)$ & $8(4.0)$ & $4(8.9)$ & \\
\hline Affected extremity & & & & 0.692 \\
\hline Upper extremity & $55(22.4)$ & $45(22.5)$ & $10(22.2)$ & \\
\hline Lower extremity & $174(71.0)$ & $143(71.5)$ & 31 (68.9) & \\
\hline Both & $14(5.7)$ & $10(5.0)$ & $4(8.9)$ & \\
\hline Others $^{a}$ & $2(0.8)$ & $2(1.0)$ & $0(0.0)$ & \\
\hline Unilateral & $224(91.4)$ & $183(91.5)$ & 41 (91.1) & 0.891 \\
\hline Engaged in military service & $95(38.8)$ & 95 (47.5) & $0(0.0)$ & $<0.001$ \\
\hline
\end{tabular}

Values are presented as median (interquartile range) or number (\%).

CRPS: complex regional pain syndrome, NRS: numerical rating scale.

${ }^{a}$ There were 2 patients with suspicious CRPS whose pain was complained in the scrotum and face.

and $P<0.001$, respectively). With regard to the type of CRPS, CRPS type I was more common in both groups; however, it was significantly more frequent in the military service group than in the non-military service group $(94.7 \%$ vs. $82.9 \%$; $P=0.016$ ). Etiology relevant to CRPS was different between the groups. In the non-military service group, surgical procedure was the most common cause (34.6\%), followed by contusion/crush injury (20.2\%) and traffic accident (18.1\%). However, sprain/strain was the most common etiology in the military service group $(40.0 \%)$ and traffic accidents were not a cause in any of the patients in this group $(0.0 \%)$. Although the incidence was higher in the lower extremities than in the upper extremities in both service groups, it was significantly more frequent in the military service group than in the non-military service group ( $84.2 \%$ vs. $60.0 \% ; P=0.001)$. When symptoms and signs relevant to CRPS, such as sensory abnormality, skin color difference and temperature difference between the affected and contralateral extremities, edema, motor dysfunction, trophic change, and sweating were explored, there was no difference between the military service and non-military service groups with regard to any of these parameters (Fig. 2). Sensory abnormality was the most commonly observed symptom and sign in the young male CRPS population. Interestingly, the second most common symptom that patients complained of was motor dysfunction, whereas the second most common objective sign was temperature difference.
Out of the 200 male CRPS patients, NRS pain scores from the initial to the last visits of $161(80.5 \%)$ patients were available. These patients were divided into 2 groups according to their treatment outcome, which was predefined as a pain reduction of more than $50 \%$ or a decrease of more than 3 NRS points [13] or an NRS score $\leq 4$ on the last outpatient visit. Among the patients, 61 patients (37.9\%) were classified as the "Success group" and the remaining 100 patients (62.1\%) as the "Fail group" (Table 3). The proportion of military service members was significantly higher in the Success group than in the Fail group (57.4\% vs. $38.0 \%, P=0.026$ ). There were no significant differences in the age, duration of pain, CRPS type, pain severity at the initial visit, affected site, and treatment modality (except SCS implantation) between the outcome groups; more patients in the Fail group had undergone SCS implantation than those in the Success group $(27.0 \%$ vs. $11.5 \%$; $P=$ 0.032). In terms of management of CRPS in young male patients, sympathetic block was the most frequent procedure $(70.8 \%)$ and more than half $(52.2 \%)$ the patients had taken opioid medication for pain management.

The results of multivariable logistic regression analysis for successful treatment outcome in male CRPS patients are shown in Table 4. In univariable analyses, age, duration of pain, the initial NRS pain score, relevance to military service, occurance in a lower extremity, opioid medication, and SCS implantation showed trends suggestive of statistical significance $(P<0.2)$. However, in multivariable 
Table 2. Characteristics of Male CRPS Patients according to Their Military Service Association

\begin{tabular}{|c|c|c|c|}
\hline Relevance to military service & $\begin{array}{l}\text { Non-military } \\
\text { service group } \\
\quad(n=105)\end{array}$ & $\begin{array}{c}\text { Military } \\
\text { service group } \\
(n=95)\end{array}$ & $P$ value \\
\hline Age (yr) & $22(20-26)$ & $21(20-23)$ & 0.024 \\
\hline Duration (mo) & $10(6-22)$ & $7(4-12)$ & $<0.001$ \\
\hline CRPS type I/type II & $\begin{array}{l}87(82.9) / \\
18(17.1)\end{array}$ & $\begin{array}{c}90(94.7) / \\
5(5.3)\end{array}$ & 0.016 \\
\hline Initial NRS pain score $(0-10)$ & $7(6-9)$ & $7(6-8)$ & 0.370 \\
\hline Etiology & & & $<0.001$ \\
\hline Sprain/Strain & $10(9.5)$ & $38(40.0)$ & \\
\hline Post-surgical & $36(34.3)$ & $18(18.9)$ & \\
\hline Fractures & $4(3.8)$ & $2(2.1)$ & \\
\hline Contusion/Crush injury & $21(20.0)$ & $24(25.3)$ & \\
\hline Local inflammation & $3(2.9)$ & $0(0.0)$ & \\
\hline Traffic accident & $19(18.1)$ & $0(0.0)$ & \\
\hline Spontaneous & $6(5.7)$ & $11(11.6)$ & \\
\hline Other or unknown & $5(4.8)$ & $2(2.1)$ & \\
\hline Affected extremity & & & 0.001 \\
\hline Upper extremity & $31(29.5)$ & $14(14.7)$ & \\
\hline Lower extremity & $63(60.0)$ & $80(84.2)$ & \\
\hline Both & $9(8.6)$ & $1(1.1)$ & \\
\hline Others ${ }^{a}$ & $2(1.9)$ & $0(0.0)$ & \\
\hline Unilateral/Bilateral & $\begin{array}{c}96(91.4) / \\
9(8.6)\end{array}$ & $\begin{array}{c}87(91.6) / \\
8(8.4)\end{array}$ & 0.634 \\
\hline Psychiatric treatments ${ }^{\mathrm{b}}$ & $29(27.6)$ & $19(20.0)$ & 0.274 \\
\hline Previously treated hospital & & & 0.065 \\
\hline None & $5(4.8)$ & $1(1.1)$ & \\
\hline Primary care clinic & $9(8.6)$ & $11(11.6)$ & \\
\hline Secondary care hospital & $47(44.8)$ & $56(58.9)$ & \\
\hline Tertiary care hospital & $44(41.9)$ & $27(28.4)$ & \\
\hline Treatment previously received & & & 0.897 \\
\hline None & $13(12.4)$ & $10(10.5)$ & \\
\hline Medications or physical therapies & 45 (42.9) & $43(45.3)$ & \\
\hline Interventions ${ }^{c}$ & $47(44.8)$ & $42(44.2)$ & \\
\hline
\end{tabular}

Values are presented as median (interquartile range) or number (\%). CRPS: complex regional pain syndrome, NRS: numerical rating scale. ${ }^{a}$ There were 2 patients with suspicious CRPS whose pain was complained in the scrotum and face. ${ }^{b}$ Any history of being treated by a psychiatrist in Seoul National University Hospital after CRPS diagnosis. Injection treatments including epidural block, sympathetic nerve block and peripheral nerve block.

analysis, moderate and severe initial pain scores (odds ratio $[\mathrm{OR}]=0.14 ; 95 \%$ confidence interval $[\mathrm{CI}], 0.02-0.84 ; P=$ 0.032 and $\mathrm{OR}=0.12 ; 95 \% \mathrm{CI}, 0.02-0.74 ; P=0.022$, respectively) and relevance to military service ( $\mathrm{OR}=2.07 ; 95 \% \mathrm{CI}$, 1.04-4.13; $P=0.039$ ) were identified as independent predictors of the treatment outcome.

\section{DISCUSSION}

In this study, we investigated the clinical characteristics of CRPS in the young population of South Korea and ex- plored the characteristics of CRPS among young male patients, particularly with regard to their military service status. This is the first study to investigate the characteristics of young male patients under the age of 30 years diagnosed with CRPS using the Budapest research criteria and the use of a homogeneous standardized assessment protocol. The results of our study indicated that CRPS was more common in young adult male than in young adult female, with a male to female ratio of 2.2:1.0. Among these male patients, $47.5 \%$ were diagnosed with CRPS during their military service period. Pain from CRPS was more common in the lower extremity; this was particularly more prominent in military service members than in nonmilitary members. In terms of etiology, surgery was the most frequent cause of CRPS in male patients, whereas traffic accident was the most frequent cause in female patients. However, in the military service members, sprain/ strain was the most common cause, accounting for $40 \%$ of the cases. A comparison of military and non-military service members showed that there were a higher number of younger patients with a shorter duration of disease in the military service members than in the non-military service members. In the overall population in this study, CRPS type I was more prevalent than CRPS type II, with a ratio of 6.4:1.0, and this was significantly higher in the military service members than in non-military service members. Multivariable analysis revealed independent associations of relevance to military service with successful treatment outcome.

Our results differ from those of previous studies conducted in other countries, particularly with regard to sex distribution. Previous studies have usually shown that CRPS is more common in females with the female to male ratio ranging from 2:1 to 4:1 [1]. In another recent largescale national study of the Korean population, it was seen that CRPS was more frequent in female patients than in male patients, although the female to male ratio was not as pronounced as in the previous studies (1.3:1.0) [4]. However, in our study, where we have intensively investigated 245 young patients under the age of 30 years with CRPS, we found that the prevalence of CRPS in male patients was more than twice that in female patients. Although a similar finding was noted by Choi et al. [5], they included only 22 patients in the third decade and therefore, their study may not be representative of sex distribution in the young Korean population with CRPS. Therefore, the results of our epidemiological study may be the first to report a reverse sex distribution of CRPS in the young population of Korea.

One of the notable findings in this study was that the diagnosis rate of CRPS among subjects who underwent testing for CRPS was relatively higher in the younger population compared to the previous data suggested by 

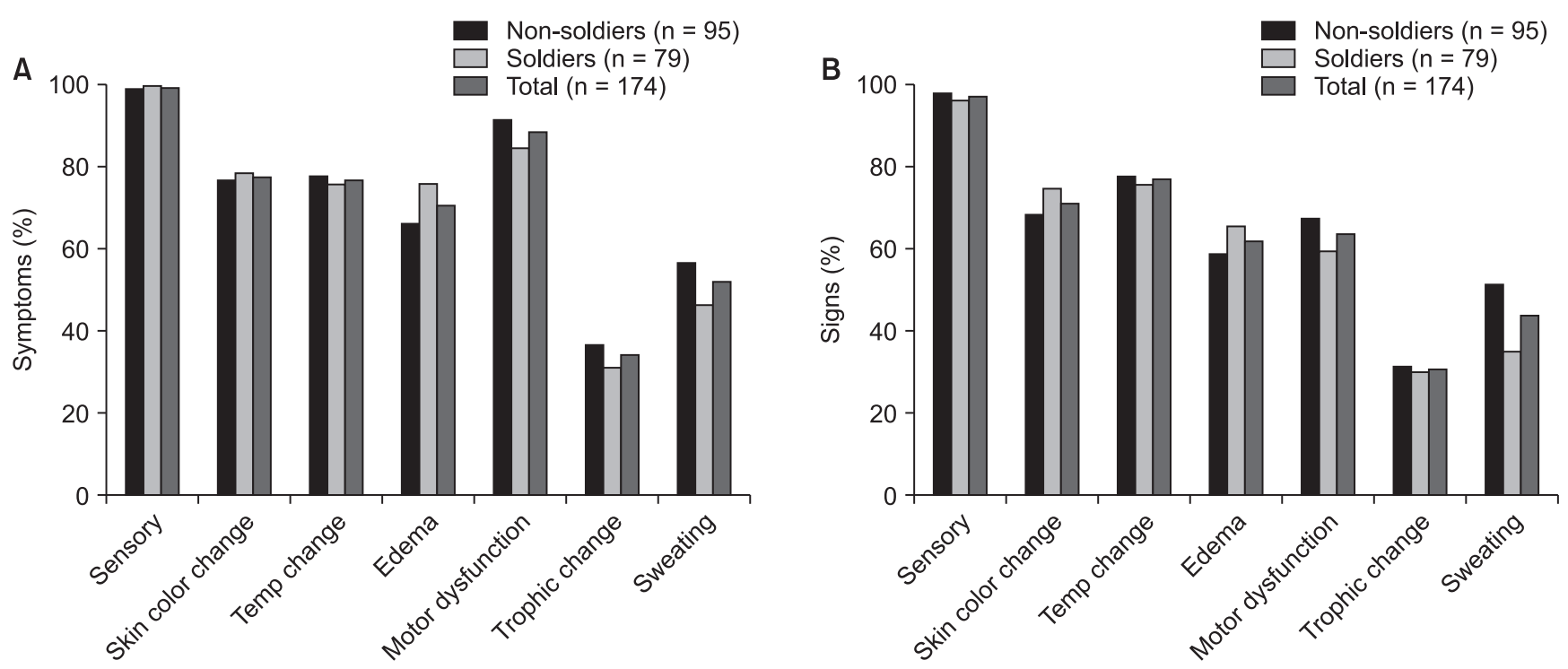

Fig. 2. Complex regional pain syndrome symptoms (A) and signs (B) according to the relevance of military service. Sensory: sensory abnormality such as spontaneous pain, hyperalgesia and/or allodynia, Skin color change: Skin color difference between the affected and contralateral extremities, Temp change: temperature difference between the affected and contralateral extremities.

Table 3. Treatment Outcome in Young Male CRPS Patients

\begin{tabular}{|c|c|c|c|}
\hline Variable & $\begin{array}{c}\text { Fail } \\
(n=100)\end{array}$ & $\begin{array}{l}\text { Success } \\
(n=61)\end{array}$ & $P$ value \\
\hline Age (yr) & $22(20-26)$ & $21(20-22)$ & 0.085 \\
\hline Duration (mo) & $8(4-21)$ & $7(4-10)$ & 0.080 \\
\hline CRPS type I/type II & $\begin{array}{l}86(86.0) / \\
14(14.0)\end{array}$ & $\begin{array}{c}55(90.2) / \\
6(9.8)\end{array}$ & 0.596 \\
\hline NRS at first visit & & & 0.057 \\
\hline Mild (NRS 1-4) & $2(2)$ & $6(9.8)$ & \\
\hline Moderate (NRS 5-7) & $46(46)$ & $30(49.2)$ & \\
\hline Severe (NRS 8-10) & $52(52)$ & $25(41.0)$ & \\
\hline Outpatient treatment period (mo) & $20.5(5-53.5)$ & $23(8-47.3)$ & 0.488 \\
\hline Relevance to military service & & & 0.026 \\
\hline No & $62(62.0)$ & $26(42.6)$ & \\
\hline Yes & $38(38.0)$ & $35(57.4)$ & \\
\hline Affected extremity & & & 0.458 \\
\hline Upper extremity & $25(25.0)$ & $11(18.0)$ & \\
\hline Lower extremity & $68(68.0)$ & $48(78.7)$ & \\
\hline Both & $6(6.0)$ & $2(3.3)$ & \\
\hline Others & $1(1.0)$ & $0(0.0)$ & \\
\hline \multicolumn{4}{|l|}{ Treatment Modality } \\
\hline Opioid use & $57(57.0)$ & $27(44.3)$ & 0.159 \\
\hline Anticonvulsants use & $76(76.0)$ & $50(82.0)$ & 0.488 \\
\hline Antidepressant use & $51(51.0)$ & $32(52.5)$ & 0.986 \\
\hline Sympathetic block & $68(68.0)$ & $46(75.4)$ & 0.410 \\
\hline Epidural block & $22(22.0)$ & $12(19.7)$ & 0.879 \\
\hline SCS implantation & $27(27.0)$ & 7 (11.5) & 0.032 \\
\hline IDDS & $1(1.0)$ & $0(0.0)$ & 1.000 \\
\hline
\end{tabular}

Values are presented as median (interquartile range) or number (\%). CRPS: complex regional pain syndrome, NRS: numerical rating scale, SCS: spinal cord stimulator, IDDS: intrathecal drug delivery system. the same clinic (68.8\% vs. $49.5 \%$, respectively) [5]. We used the Budapest research criteria for all cases from 2007 in a standardized manner through objective evaluation so that at least one symptom from all 4 categories (sensory, vasomotor, sudomotor/edema, and motor/trophic dysfunction) and at least 2 signs from the same 4 categories had to be satisfied for a diagnosis of CRPS [14]. When we compared our results to those of the previous study [5], the presence of CRPS signs was much higher in the current study than that in the previous one in all sign categories, such as skin color change $(70.4 \%$ in this study vs. $45.3 \%$ in the former study), edema ( $61.4 \%$ vs. $37.9 \%)$, asymmetry in sweating (43.8\% vs. $22.1 \%)$, etc. Although symptoms and signs may change over time and vary from person to person, pain, swelling, redness, noticeable changes in temperature and hypersensitivity usually occur in the earlier phase of CRPS [15]. Although further studies are required to investigate this, we think that the relatively short duration of CRPS in the younger population in this study may be associated with the high prevalence of symptoms and signs, which accounts for the high rate of CRPS diagnosis.

The most noteworthy aspect of this study is that nearly half of all male patients in the younger age group were diagnosed with CRPS during their military service period. In the previous Korean epidemiological study [5], it was suggested that CRPS was common in the third decade because of the high risk of trauma during military service. However, there has been no study to date that has investigated the association between CRPS and military service status. A study that investigated the relationship between the incidence of CRPS and the patient's occupation in 
Table 4. Multivariable Logistic Regression Analysis for Factors Associated with Treatment Outcome in Young Male CRPS Patients $(n=161)$

\begin{tabular}{|c|c|c|c|c|}
\hline \multirow{2}{*}{ Variable } & \multicolumn{2}{|c|}{ Univariate analysis } & \multicolumn{2}{|c|}{ Multivariate models } \\
\hline & $P$ value & Odds ratio $(95 \% \mathrm{Cl})$ & $P$ value & Odds ratio $(95 \% \mathrm{Cl})$ \\
\hline Age & 0.044 & $0.90(0.81-1.00)$ & & \\
\hline Duration & 0.064 & $0.98(0.95-1.00)$ & 0.082 & $0.98(0.95-1.00)$ \\
\hline CRPS type II (vs. type I) & 0.439 & $0.67(0.24-1.85)$ & & \\
\hline \multicolumn{5}{|l|}{ NRS } \\
\hline Mild (NRS 1-4) & 0.089 & - & 0.073 & \\
\hline Moderate (NRS 5-7) & 0.072 & $0.22(0.04-1.15)$ & 0.032 & $0.14(0.02-0.84)$ \\
\hline Severe (NRS 8-10) & 0.032 & $0.16(0.03-0.85)$ & 0.022 & $0.12(0.02-0.74)$ \\
\hline Military service & 0.017 & $2.20(1.15-4.20)$ & 0.039 & $2.07(1.04-4.13)$ \\
\hline Lower extremity (vs. others) & 0.145 & $1.74(0.83-3.65)$ & & \\
\hline Opioid medications & 0.118 & $0.60(0.32-1.14)$ & & \\
\hline Antidepressant medications & 0.857 & $1.06(0.56-2.01)$ & & \\
\hline Anticonvulsant medications & 0.375 & $1.44(0.65-3.19)$ & & \\
\hline Sympathetic block & 0.317 & $1.44(0.70-2.96)$ & & \\
\hline Epidural block & 0.726 & $0.87(0.39-1.91)$ & & \\
\hline SCS implantation & 0.023 & $0.35(0.14-0.86)$ & 0.091 & $0.44(0.17-1.14)$ \\
\hline
\end{tabular}

Variables showing a trend towards statistical significance $(P<0.2)$ in the univariate analysis were included in multivariable logistic regression. CRPS: complex regional pain syndrome, Cl: confidence interval, NRS: numerical rating scale, SCS: spinal cord stimulator.

134 patients in tertiary hospitals in the USA reported that CRPS was almost twice as prevalent in restaurant workers and police officers as in patients with other occupations [7]. They suggested that occupational physical activity might be related to the development of CRPS [7]. Soldiers face a higher risk of trauma due to greater exposure to intense training, exercise, and work, as compared to the general population [16-18]. We suspect that vigorous activity during military service may have led to the higher incidence of CRPS in this subgroup.

In the previous Korean epidemiologic study, it was suggested that CRPS was common in the third decade because of the high risk of trauma during military service [5]. The most common etiology of CRPS in our military service group was the sprain/strain of soft tissue, which was different from that in the young female patients in this study and in patients in a previous study (traffic accident was most common in both) $[5,19]$. In another epidemiological study of 303 young male in the US army, 37\% of the subjects experienced lower extremity injury during their service period and the most common cause was strain and sprain [20]. In another study that evaluated the prevalence of injury in Greek army officer cadets, ankle/foot strain and sprain were reported to be the most common injuries during basic combat training [21]. The military service members in the current study had a higher incidence of CRPS in their lower extremities compared to the non-military service group, which can be attributed to the sprain/ strain of soft tissues. Therefore, we suggest that relatively common injuries in the lower extremity caused by sprain/ strain during military service may have affected the epi- demiology of CRPS in this study.

The high risk of trauma in the army may not be the only reason why CRPS occurs commonly in soldiers. Another factor to be addressed in military service is social stress due to the obligation to enlist. In Korea, it has been reported that military soldiers who have to compulsorily enlist due to the conscription system have a high psychological burden [22]. In a study conducted in Korean conscripts with lumbar disc herniation, there were more psychological problems, such as depression and anxiety, in conscripts compared to healthy controls, which were associated with functional availability [23]. Another study has reported that social stress around the time of the manifestation is a risk factor for the development of CRPS [24]. In addition, CRPS patients experienced more stressful life events prior to being affected by the condition [25]. Although psychological co-morbidity may not have a role in poor prognosis in CRPS, it is widely accepted that it plays a role in the development of the disease $[26,27]$. However, when we compared the differences in NRS pain scores from the initial to the final visit in male CRPS patients, military service members showed better treatment outcomes than non-military service members. This result may not be easily explained; however, we presume that the shorter duration of CRPS from the symptomatic manifestation to the hospital visit might have led to the better treatment outcomes in the military service group in this study. Besides, it is carefully suggested that psychological release alongside the wind-up of the military obligation may yield a better treatment outcome in this exceptional group. Although no studies have reported the association 
between the psychological stress from obligatory military service and the prevalence or clinical outcomes of CRPS, a previous study conducted in Korean soldiers showed that depression was inversely proportional to the remaining service period [28]. Therefore, further study is warranted regarding the effects of psychological stress from obligatory military service on the development of CRPS.

This study has several limitations. First is the inherent limitation of the retrospective study design; all data were not available due to insufficient records or loss of followup. Second, although only a limited number of hospitals professionally evaluate and manage CRPS in Korea, our results were obtained from a single tertiary university hospital, and therefore, it is difficult to fully generalize the findings. Third, we could not include variables that would be relevant to the outcome of CRPS, such as the results of psychological evaluations, litigation status, existence of secondary gain, any type of reimbursement, etc. In addition, this study would have been more sophisticated if the details of the military service could be analyzed, for example, the status of hierarchy in the army (e.g., status as a private or an officer), whether the soldier's enlistment was voluntary or if it was enforced compulsory service, the soldier's tour of duty, whether the patient was discharged from the army due to CRPS itself, etc.

In conclusion, our results demonstrated that the manifestation of CRPS in the young Korean population was more common in male and among these male CRPS patients, about half the cases manifested during the military service period. CRPS in the lower extremity due to sprain/ strain was the most common type in the military service members. Therefore, various measures are needed to reduce sprain/strain in these populations, and if CRPS is suspected, a system for early diagnosis and treatment during the military service would be triggered. Further investigation with a large-scale epidemiological study of CRPS in the young Korean population, with particular consideration of unique groups, such as military service members, should be carried out to better interpret the results.

\section{CONFLICT OF INTEREST}

No potential conflict of interest relevant to this article was reported.

\section{ORCID}

Ho-Jin Lee, https://orcid.org/0000-0002-7134-5044

Chang-Soon Lee, https://orcid.org/0000-0001-6810-5130

Yongjae Yoo, https://orcid.org/0000-0002-9097-6167
Jae Mun Noh, https://orcid.org/0000-0002-4242-3146

Je Hyuk Yu, https://orcid.org/0000-0002-6388-6676

Yong-Chul Kim, https://orcid.org/0000-0002-8461-5322

Jee Youn Moon, https://orcid.org/0000-0001-5551-7750

\section{REFERENCES}

1. McMahon SB, Koltzenburg M, Tracey I, Turk D. Wall \& Melzack's textbook of pain. 6th ed. Philadelphia, Elsevier Saunders. 2013, pp 961-77.

2. Galer BS, Henderson J, Perander J, Jensen MP. Course of symptoms and quality of life measurement in complex regional pain syndrome: a pilot survey. J Pain Symptom Manage 2000; 20: 286-92.

3. Benzon H, Raja SN, Fishman S, Liu S, Cohen SP. Essentials of pain medicine. 3rd ed. Philadelphia, Elsevier Saunders. 2011, p 351.

4. Kim H, Lee CH, Kim SH, Kim YD. Epidemiology of complex regional pain syndrome in Korea: an electronic population health data study. PLoS One 2018; 13: e0198147.

5. Choi YS, Lee MG, Lee HM, Lee CJ, Jo JY, Jeon SY, et al. Epidemiology of complex regional pain syndrome: a retrospective chart review of 150 Korean patients. J Korean Med Sci 2008; 23: 772-5.

6. Veldman PH, Reynen HM, Arntz IE, Goris RJ. Signs and symptoms of reflex sympathetic dystrophy: prospective study of 829 patients. Lancet 1993; 342: 1012-6.

7. Allen G, Galer BS, Schwartz L. Epidemiology of complex regional pain syndrome: a retrospective chart review of 134 patients. Pain 1999; 80: 539-44.

8. Stanton-Hicks M, Jänig W, Hassenbusch S, Haddox JD, Boas R, Wilson P. Reflex sympathetic dystrophy: changing concepts and taxonomy. Pain 1995; 63: 127-33.

9. Military Manpower Administration. 2017 Military statistical yearbook (No. 47). Daejeon: Military Manpower Administration; 2018. Available at: https://www.mma.go.kr/download/ ebook/2017_yeartgyb.pdf.

10. Von Elm E, Altman DG, Egger M, Pocock SJ, Gøtzsche PC, Vandenbroucke JP. The Strengthening the Reporting of Observational Studies in Epidemiology (STROBE) statement: guidelines for reporting observational studies. Lancet 2007; 370: 1453-7.

11. Harden RN, Bruehl S, Perez RS, Birklein F, Marinus J, Maihofner $\mathrm{C}$, et al. Validation of proposed diagnostic criteria (the "Budapest Criteria") for complex regional pain syndrome. Pain 2010; 150: 268-74.

12. Park SH, Lee PB, Lim YH, Lee SY, Choi IY, Lee SJ, et al. The usefulness of three-phase bone scan and thermography for making the diagnosis of CRPS-I. Korean J Pain 2006; 19: 81-6.

13. Forouzanfar T, Weber WE, Kemler M, van Kleef M. What is a meaningful pain reduction in patients with complex re- 
gional pain syndrome type 1? Clin J Pain 2003; 19: 281-5.

14. Harden RN, Bruehl S, Stanton-Hicks M, Wilson PR. Proposed new diagnostic criteria for complex regional pain syndrome. Pain Med 2007; 8: 326-31.

15. Birklein F, Riedl B, Claus D, Neundörfer B. Pattern of autonomic dysfunction in time course of complex regional pain syndrome. Clin Auton Res 1998; 8: 79-85.

16. Lauder TD, Baker SP, Smith GS, Lincoln AE. Sports and physical training injury hospitalizations in the army. Am J Prev Med 2000; 18(3 Suppl): 118-28.

17. Knapik JJ, Hauret KG, Canada S, Marin R, Jones B. Association between ambulatory physical activity and injuries during United States Army basic combat training. J Phys Act Health 2011; 8: 496-502.

18. Davidson PL, Chalmers DJ, Wilson BD, McBride D. Lower limb injuries in New Zealand Defence Force personnel: descriptive epidemiology. Aust N Z J Public Health 2008; 32: 167-73.

19. Dev S, Yoo Y, Lee HJ, Kim DH, Kim YC, Moon JY. Does temperature increase by sympathetic neurolysis improve pain in complex regional pain syndrome? A retrospective cohort study. World Neurosurg 2018; 109: e783-91.

20. Jones BH, Cowan DN, Tomlinson JP, Robinson JR, Polly DW, Frykman PN. Epidemiology of injuries associated with physical training among young men in the army. Med Sci Sports Exerc 1993; 25: 197-203.
21. Havenetidis K, Kardaris D, Paxinos T. Profiles of musculoskeletal injuries among Greek Army officer cadets during basic combat training. Mil Med 2011; 176: 297-303.

22. Hyun HS, Lee IS. A study on stress and symptoms of stress in soldiers in the army. J Korean Acad Nurs 2008; 38: 238-47.

23. Kim TS, Pae CU, Hong CK, Kim JJ, Lee CU, Lee SJ, et al. Interrelationships among pain, disability, and psychological factors in young Korean conscripts with lumbar disc herniation. Mil Med 2006; 171: 1113-6.

24. Raja SN, Grabow TS. Complex regional pain syndrome I (reflex sympathetic dystrophy). Anesthesiology 2002; 96: 125460.

25. Geertzen JH, de Bruijn-Kofman AT, de Bruijn HP, van de Wiel HB, Dijkstra PU. Stressful life events and psychological dysfunction in complex regional pain syndrome type I. Clin J Pain 1998; 14: 143-7.

26. Brunner F, Nauer M, Bachmann LM. Poor prognostic factors in complex regional pain syndrome 1: a delphi survey. J Rehabil Med 2011; 43: 783-6.

27. Wertli M, Bachmann LM, Weiner SS, Brunner F. Prognostic factors in complex regional pain syndrome 1: a systematic review. J Rehabil Med 2013; 45: 225-31.

28. Woo CH, Park JY. A study on comparison of classification and regression tree and multiple regression for predicting of soldiers' depression. J Korean Acad Psychiatr Ment Health Nurs 2014; 23: 268-77. 